divisions deal respectively with medicine, education and science. The last-named section gives, as is natural, much of its space to the story of phlogiston and to the discovery and manipulation of gases. Sections on authors and booksellers and on the newspaper close a study which provides material of most absorbing interest, and which may fairly be called indispensable to a student of the period. It will none the less prove attractive to the general reader and will receive an unstinted welcome from all sound Johnsonians. We hope that Prof. Turberville will continue the good work -a study of Tennyson's England covers almost the same period in the nineteenth century that is covered in the eighteenth by the present study, and it has its possibilities.

\title{
Manufacture of Sheet and Plate Glass
}

IN a Friday evening discourse delivered at the 1 Royal Institution on December 8, Major R. M. Weeks, of Messrs. Pilkington Brothers, Ltd., described, and illustrated by lantern slides and films, the methods in use for the manufacture of sheet and plate glass.

The principal raw materials used in the manufacture of sheet and plate glass are sand, soda ash and limestone. These materials, perhaps with the addition of arsenic, anthracite, alumina or magnesium carbonate, all in a finely divided condition, are intimately mixed prior to melting. There are two well-known processes for melting this mixture. (1) The older method, in which the materials are melted in clay pots, and a definite time-temperature schedule is allotted to melting, founding, refining and cooling off to the working temperature. As many as twenty melting pots are sometimes accommodated in one furnace. (2) The more modern method, in which the mixed raw materials are fed on at one end of a tank furnace where they are melted. The molten glass then flows through controlled temperature zones which ensure the founding and refining, and finally arrive at the working end at the required temperature. Such tanks contain anything up to 900 tons, and the temperatures may vary from $1450^{\circ}$ to $1200^{\circ} \mathrm{C}$. in different zones.

Sheet glass was first made by a blowing and spinning process. Such glass, known as 'crown glass', was characterised by the 'bull's eye' in the middle of each disc. This method was followed in 1832 by the 'blown' process, in which the gathering of glass was blown into the form of an elongated cylinder. After separating the cylinder from the blowing iron, the ends were cut off, and the cylinder split down its length and flattened into a sheet. In 1909, a mechanical method of drawing cylinders of a larger size was introduced from the United States. By this method, cylinders $40 \mathrm{ft}$. long and about $3 \mathrm{ft}$. in diameter are drawn (Fig. 1). Such cylinders are cut up into sections before flattening and annealing.

Since 1900, three processes for the drawing of flat sheet glass have been developed commercially : (a) Fourcault process, (b) Colburn or LibbeyOwens, and (c) Pittsburg process. In the Fourcault process, glass is drawn as a sheet vertically from a slot in a depressed fireclay float. In its early days, devitrification was a source of trouble. In the Libbey-Owens process the sheet is drawn from an open bath of molten glass, and thus excessive devitrification troubles are avoided, but the sheet when formed is reheated and bent to the horizontal by being passed over a bending roller. The Pittsburg process is a modification of the Fourcault process, the chief difference lying in the use of a bar of fireclay submerged beneath the surface of the glass to define the position of generation of the sheet.

The making of plate glass involves two distinct

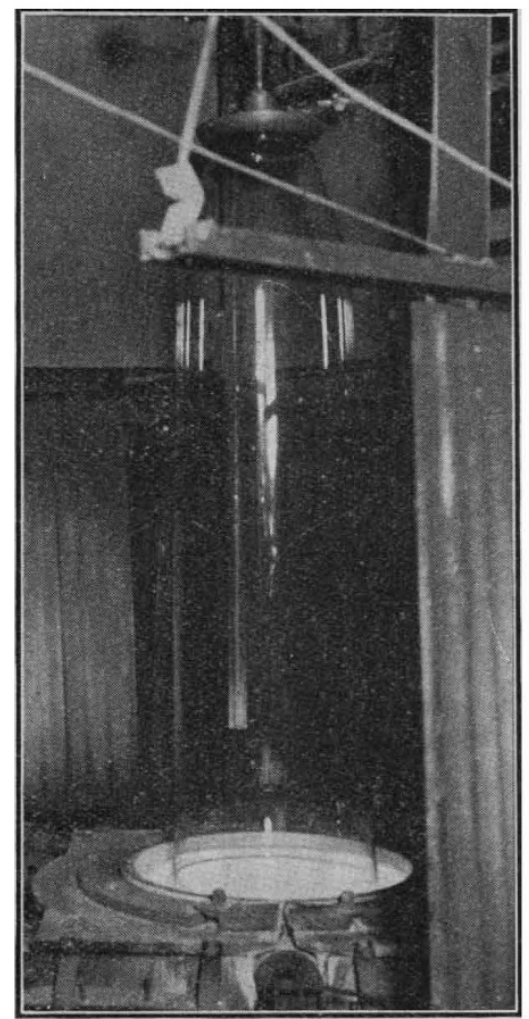

Fig. 1. Drawing sheet glass cylinders mechanically.

processes : (1) manufacture of rough glass blanks ; and (2) grinding and polishing of these blanks. Since 1774, plate glass blanks have been cast from glass melted in pots. Typical melting pots contain about a ton of glass and yield plates of about 300 square feet, at a thickness of $7 / 16$ of an inch. The casting consists in taking the pot from the furnace and pouring the molten glass on to a smooth iron table in front of a roller. The rolled blank is then annealed, a process which in earlier times occupied three 
days, but now, for a blank $\frac{1}{2}$ in. thick, occupies $2 \frac{1}{2}$ hours.

A modern modification of this process, due to flatter sheet than the older single roller process ; consequently, there is less loss of material and a reduced time required for the grinding process.

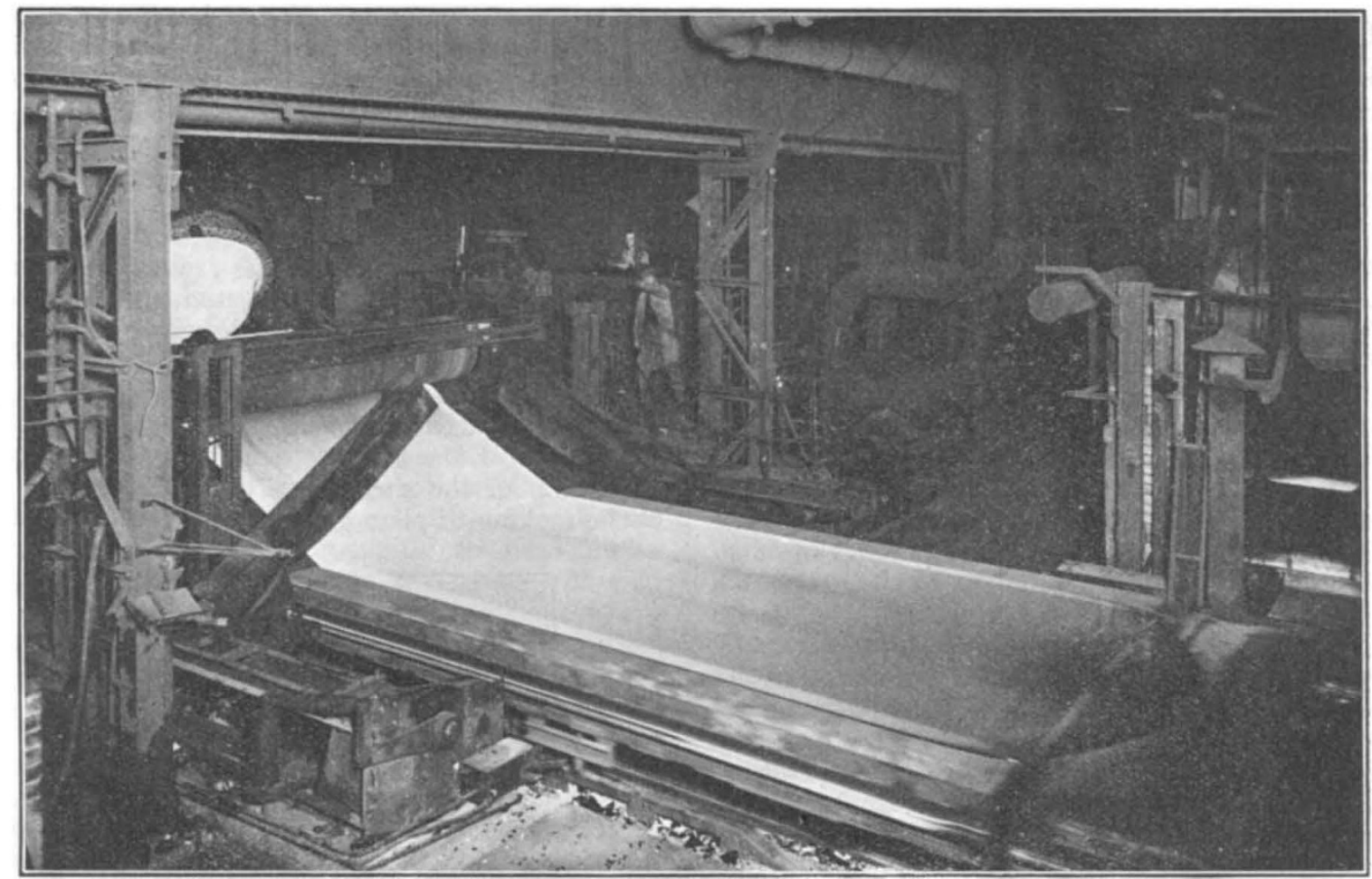

FIG. 2. Casting plate glass blanks by the Bicheroux process.

Bicheroux, consists in pouring the molten glass between two rollers on to a moving table (Fig. 2). The irregular beginning and end of the sheet are

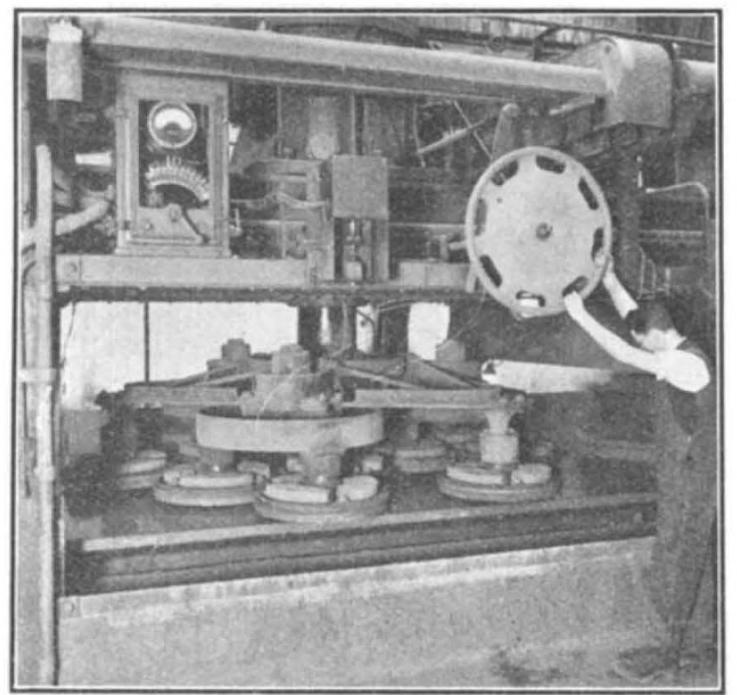

FIG. 3. Polishing plate glass.

cut off while still hot by a guillotine and the trimmed sheet is then passed into an annealing lehr, from which it later emerges ready for cutting and polishing. This process gives a smoother and
The most modern process of all is a modification of the Bicheroux process, and consists in the continuous discharge of a stream of glass from a tank furnace between a pair of forming rolls, from which it issues in the form of a continuous ribbon or sheet, which passes over a roller bed and through an annealing lehr.

In the second stage of the process of preparing plate glass, namely, grinding and polishing, the grinding is accomplished by using progressively finer grades of sand fed with water, under cast iron runners. This is continued until a frosted surface of the finest possible texture is obtained. The polishing process is then begun and consists in rubbing the glass with felt dises fed with carefully prepared rouge (Fig. 3). All plate glass used to be, and much still is, ground and polished on rotating tables on which the glass is embedded, but this method has been superseded by a continuous process.

Machines used in this continuous grinding and polishing process are very large and expensive units; some are so much as $800 \mathrm{ft}$. long by $15 \mathrm{ft}$. wide.

Two recent developments of note in flat glass manufacture are (1) coloured opaque glass known as "Vitrolite" and (2) toughened plate glass known as "Armourplate". The latter is made by the suitable heat treatment of ordinary plate glass.

S. E. 